\title{
Mammalian Clusterin associated protein 1 is an evolutionarily conserved protein required for ciliogenesis
}

\author{
Raymond C Pasek ${ }^{1}$, Nicolas F Berbari ${ }^{1}$, Wesley R Lewis ${ }^{1}$, Robert A Kesterson ${ }^{2}$ and Bradley K Yoder ${ }^{1 *}$
}

\begin{abstract}
Background: Clusterin associated protein 1 (CLUAP1) was initially characterized as a protein that interacts with clusterin, and whose gene is frequently upregulated in colon cancer. Although the consequences of these observations remain unclear, research of CLUAP1 homologs in C. elegans and zebrafish indicates that it is needed for cilia assembly and maintenance in these models. To begin evaluating whether Cluap1 has an evolutionarily conserved role in cilia in mammalian systems and to explore the association of Cluap1 with disease pathogenesis and developmental abnormalities, we generated Cluap1 mutant mice.
\end{abstract}

Methods: Cluap1 mutant embryos were generated and examined for gross morphological and anatomical defects using light microscopy. Reverse transcription PCR, $\beta$-galactosidase staining assays, and immunofluorescence analysis were used to determine the expression of the gene and localization of the protein in vivo and in cultured cell lines. We also used immunofluorescence analysis and qRT-PCR to examine defects in the Sonic hedgehog signaling pathway in mutant embryos.

Results: Cluap1 mutant embryos die in mid-gestation, indicating that it is necessary for proper development. Mutant phenotypes include a failure of embryonic turning, an enlarged pericardial sac, and defects in neural tube development. Consistent with the diverse phenotypes, Cluap1 is widely expressed. Furthermore, the Cluap1 protein localizes to primary cilia, and mutant embryos were found to lack cilia at embryonic day 9.5. The phenotypes observed in Cluap1 mutant mice are indicative of defects in Sonic hedgehog signaling. This was confirmed by analyzing hedgehog signaling activity in Cluap1 mutants, which revealed that the pathway is repressed.

Conclusions: These data indicate that the function of Cluap1 is evolutionarily conserved with regard to ciliogenesis. Further, the results implicate mammalian Cluap1 as a key regulator of hedgehog signaling and as an intraflagellar transport B complex protein. Future studies on mammalian Cluap1 utilizing this mouse model may provide insights into the role for Cluap1 in intraflagellar transport and the association with colon cancer and cystic kidney disorders.

Keywords: Intraflagellar transport, Sonic hedgehog, Clusterin associated protein 1, IFT complex B

\section{Background}

Cilia are complex organelles requiring hundreds of different genes for their assembly and function [1]. The assembly of the cilium is dependent on intraflagellar transport (IFT), a molecular motor-driven process that mediates the bidirectional movement of proteins between the base and tip of the cilium $[2,3]$. IFT was initially described in

\footnotetext{
*Correspondence: byoder@uab.edu

${ }^{1}$ Department of Cell, Developmental and Integrative Biology, University of Alabama at Birmingham, 1918 University Blvd., Birmingham, AL 35294, USA Full list of author information is available at the end of the article
}

the green algae Chlamydomonas reinhardtii and subsequently in multiple other ciliated eukaryotes, thereby suggesting a highly conserved function.

Biochemical analysis has revealed the presence of two large distinct complexes of IFT proteins termed IFT complex A and B. Complex B is thought to mediate movement in an anterograde direction toward the tip of the cilium, while IFT complex A appears to facilitate retrograde movement to bring proteins back to the cilium base $[4,5]$. Each complex is necessary for proper cilia maintenance and is important for cilia-mediated signaling activities. For

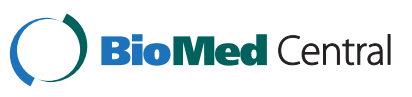


example, the Sonic hedgehog (Shh) pathway requires the cilium, with mutations in complex B proteins resulting in a repressed pathway, while complex A mutants have elevated signaling [6-9]. In humans, loss of ciliary function is responsible for a variety of diseases collectively referred to as ciliopathies [10]. The ciliopathies are characterized by a broad range of clinical features including neural tube defects, skeletal abnormalities, cystic kidneys, retinal degeneration, and obesity, just to name a few [11]. How loss of ciliary function contributes to this wide range of phenotypes is unknown. Therefore, the identification of novel mammalian IFT-associated genes and the generation of corresponding mutant models will provide insights into the ciliary connection to human disease and development defects.

In this regard, invertebrate model organisms have proven invaluable. One example can be seen in the case of $d y f-3$, a gene recently demonstrated to be necessary for proper ciliogenesis in the nematode worm C. elegans $[12,13]$. Subsequent studies demonstrated that a homo$\log$ of $d y f-3$, named qilin, is also present in zebrafish [14]. Interestingly, not only was qilin found to be necessary for cilia assembly and maintenance in zebrafish, but loss of function mutations in qilin causes a polycystic kidney disease-like phenotype similar to that observed for mutations in known IFT genes $[15,16]$. Although a Chlamydomonas homolog of DYF-3/qilin was not biochemically purified as a key component of the IFT complex, fluorescently tagged DYF-3 has been observed undergoing IFT in the cilia of $C$. elegans [17]. Further, mutations in $d y f-3$ result in ciliary defects, indicating that the protein may be a previously unrecognized component of either the IFT B or IFT A complex $[4,5,17]$.

There is also a human homolog of DYF-3/qilin, originally referred to as 'hypothetical protein KIAA0643' but later renamed clusterin associated protein 1 (CLUAP1). Cluap1 was described as a coiled-coil protein that localized to the nucleus and whose expression changed with the cell cycle. Further, CLUAP1 was commonly upregulated in numerous colorectal carcinomas, and suppression of CLUAP1 expression reduced the growth of colon cancer cells [18]. In addition, CLUAP1 interacts with clusterin, a protein induced by cell injury and elevated in cyst fluid in multiple cystic kidney disorders $[18,19]$. The cellular properties and physiological importance of CLUAP1 are unknown despite its association with the cell cycle and demonstrated alterations of CLUAP1 expression in various human disorders and diseases, as well as in vitro interaction with the protein clusterin $[18,20]$.

Based on the findings in C. elegans and zebrafish, it was hypothesized that the mammalian homolog would have roles in IFT and cilia mediated signaling. To test this hypothesis, a Cluap1 knockout mouse model was generated to assess the role of Cluap1 in an in vivo mammalian system.

\section{Methods}

\section{Generation of Cluap1 knockout allele mice}

The Cluap1 knockout allele (Cluap1 ${ }^{\text {tm1a(KOMP)Wtsi }}$, Knockout Mouse Project Repository, Davis, CA; hereinafter referred to as Cluap1 $^{K O}$ ) was generated using embryonic stem cells in which a $\beta$-galactosidase-neomycin resistance fusion cassette was inserted into intron 2 of Cluap1. The insertion site was confirmed by genomic PCR and sequence analysis. PCR primers for genotyping were designed based on the insertion site (sequences available upon request). The embryonic stem cells containing the targeted allele were on the C57BL/6 N background and were injected into albino $\mathrm{C} 57 \mathrm{BL} / 6$ blastocysts (C57BL/6 J-Tyrc-2 J; JAX Laboratories) by the UAB Transgenic Mouse Facility using standard procedures. Chimeras were then crossed with albino C57BL/6 females, and germline transmission was confirmed by the coat color of the offspring and subsequent PCR genotyping. After obtaining no homozygous mutant offspring from heterozygous matings, timed pregnancies were established to isolate embryos at the indicated gestational time point with the morning of the vaginal plug being considered embryonic day 0.5 (E0.5). Embryos were genotyped from DNA isolated from yolk sac by PCR. Mice were provided standard laboratory chow and water ad libitum. All procedures and studies involving mice were approved by the UAB Institutional Animal Care and Use Committee in accordance with regulations at the University of Alabama at Birmingham.

\section{Reverse transcription PCR analysis}

RNA was isolated from Cluap ${ }^{W T}, C l u a p 1^{\text {Het }}$, and Cluap1 $^{K O}$ E9.5 embryos with Trizol reagent according to the manufacturer's protocol (15596-026, Life Technologies, Carlsbad, CA). Once extracted, RNA was used to synthesize cDNA using the Verso cDNA kit according to the manufacturer's protocol (AB-1453, Thermo Scientific, Pittsburgh, PA). PCR analysis was then performed using the following primers (written $5^{\prime}$ to $3^{\prime}$ ), which flank the sequence between the first and last exons of the Cluap $1^{W T}$ allele: GGACTCGAGACCATGTCT and GGACCCGGGAAGAAGTCA. The following primers were also used as a positive control to confirm the presence of actin in all samples: ATGGGTCAGAAGGAC TCCTA and GGTGTAAAACGCAGCTCA. All results were confirmed by repeating the experiment in at least two additional animals.

\section{Cluap1 antibody generation}

Antisera against Cluap1 was generated in rabbits by using a 19-residue peptide (KPSRRIRKPEPLDESDNDF) 
starting at position 395 of the mouse protein according to the standard protocol established by Open Biosystems (Huntsville, AL, USA). Specificity of the antisera against Cluap1 was confirmed by Western blot analysis of protein extracts isolated from Cluap1 ${ }^{W T}$, Cluap $^{\text {Het }}$, and Cluap $1^{K O}$ embryos.

\section{Cell culture}

IMCD3 cells (ATCC, Manassas, VA) were maintained in DMEM: F12 medium supplemented with 10\% FBS, $1.2 \mathrm{~g} / \mathrm{l}$ of sodium bicarbonate, $0.5 \mathrm{mM}$ sodium pyruvate, $100 \mathrm{U} / \mathrm{ml}$ penicillin, and $100 \mathrm{mg} / \mathrm{ml}$ streptomycin. NIH3T3 cells were cultured in DMEM with 10\% FBS containing $100 \mathrm{U} / \mathrm{ml}$ penicillin and $100 \mathrm{mg} / \mathrm{ml}$ streptomycin. Creation of $176-6 \mathrm{C}$ renal epithelial cells was derived by microdissection of the cortical collecting duct segments of the kidney as previously described by Croyle et al. [21]. To induce cilia formation, cells were serum starved for $24-48 \mathrm{~h}$ prior to analysis. All cells were grown at $5 \% \mathrm{CO}_{2} / 95 \%$ air at $37^{\circ} \mathrm{C}$.

\section{Immunoblotting}

Embryonic day 9.5 embryos were isolated into ice-cold lysis buffer [137 mM NaCl, $20 \mathrm{mM}$ Tris $\mathrm{pH}$ 8.0, 1\% Triton X-100, 10\% glycerol, and complete EDTA-free protease inhibitor cocktail (Roche Diagnostics, Indianapolis, IN)]. Embryos were disrupted by passage several times through a syringe attached to a 30.5-gauge needle. The lysates were incubated on ice for $30 \mathrm{~min}$ and vortexed every $5 \mathrm{~min}$. Protein concentrations were determined by the Bradford assay (Bio-Rad Laboratories, Hercules, CA). Protein samples were resolved on a denaturing $10 \%$ Tris-HCl gel (Bio-Rad Laboratories, Hercules, CA) and transferred to an Immobilon-Psq transfer membrane (Millipore, Billerica, MA). Membranes were blocked in TBS-T (10 mM Tris-HCl, pH 7.5, $150 \mathrm{mM} \mathrm{NaCl,} \mathrm{0.1 \%}$ Tween-20) with $5 \%$ milk for $1 \mathrm{~h}$ and incubated with primary antibody diluted in TBS-T with 2\% BSA for 16$24 \mathrm{~h}$ at $4^{\circ} \mathrm{C}$. Membranes were probed with horseradish peroxidase (HRP)-conjugated secondary antibodies diluted in TBS-T with $1 \%$ milk for $1 \mathrm{~h}$ at room temperature. Secondary antibodies were detected using SuperSignal West Pico Chemiluminescent Substrate (Pierce, Waltham, MA), and bands were visualized using Blue Ultra Autorad Film (Bioexpress ISC). The following primary antibodies and dilutions were used: anti-actin (Sigma; rabbit polyclonal; 1:1,000) and anti-Cluap1 (1:1,000). The secondary antibody was HRP conjugated anti-rabbit (\#31460) and was used at 1:5,000 (Pierce/Thermo Scientific, Waltham, MA).

\section{$\beta$-galactosidase assays}

Whole kidney and heart were extracted from Cluap $1^{W T}$ and Cluap $1^{\text {Het }}$ mice at 8 weeks of age. Tissues were fixed overnight at $4^{\circ} \mathrm{C}$ in $4 \%$ PFA in PBS and subsequently washed in PBS. Tissues were then cryoprotected with $30 \%$ sucrose in PBS for $24 \mathrm{~h}$ and snap frozen in OCT freezing compound (Tissue-Tek, Torrance, CA). Tenmicron sections were cut with a Leica CM1900 cryostat, and sections were attached to Superfrost Plus microscope slides (12-550-15, Fisher Scientific, Pittsburgh, PA). Sections were postfixed in $4 \%$ PFA in PBS for $10 \mathrm{~min}$, washed three times with lacZ wash buffer (2 $\mathrm{mM} \mathrm{MgCl}_{2}, 0.01 \%$ sodium deoxycholate, $0.02 \% \mathrm{NP}-$

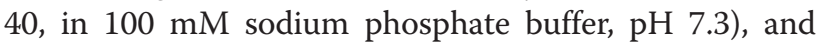
then incubated in X-gal staining solution ( $2 \mathrm{mM} \mathrm{MgCl}_{2}$, $5 \mathrm{mM}$ potassium ferrocyanide, $5 \mathrm{mM}$ potassium ferricyanide, $1 \mathrm{mg} \mathrm{ml}^{-1} \mathrm{X}$-Gal, in PBS) at $37^{\circ} \mathrm{C}$ overnight. Sections were then counterstained in Fast Red for $5 \mathrm{~min}$. Similarly, for whole-mount analyses E9.5 embryos and lung tissue from 8-week-old mice were fixed in 4\% PFA in PBS, washed three times with lac $Z$ wash buffer, and then incubated in $\mathrm{X}$-gal staining solution at $37^{\circ} \mathrm{C}$ overnight.

\section{Immunofluorescence}

Embryos and cells grown on coverslips were fixed in 4\% PFA and permeabilized with $0.3 \%$ Triton $\mathrm{X}-100$ in PBS with $2 \%$ donkey serum, $0.02 \%$ sodium azide, and $10 \mathrm{mg} /$ $\mathrm{ml}$ bovine serum albumin (BSA). Embryos were then cut to make $10-\mu \mathrm{m}$ sections. Cells and embryos were labeled with the following antibodies: anti-acetylated $\alpha$-tubulin, 1:1,000 (T-6793; Sigma-Aldrich, St. Louis, MO); antiArl13b, 1:1,000 (a gift from Dr. Tamara Caspary, Emory University); anti-Cluap1, 1:1,000 (generated as described above); and anti_ShhN, 1:1,000 (5E1, Developmental Studies Hybridoma Bank, University of Iowa, Iowa City, IA). All incubations and washes were carried out in PBS with $2 \%$ normal donkey serum, $0.02 \%$ sodium azide, and $10 \mathrm{mg} / \mathrm{ml} \mathrm{BSA}$. Primary antibody incubations were performed for $16-24 \mathrm{~h}$ at $4^{\circ} \mathrm{C}$, and secondary antibody incubations were performed for $1 \mathrm{~h}$ at room temperature. Secondary antibodies included Alexa Fluor-594 and 488 conjugated donkey anti-mouse and anti-rabbit (A-21203 and A-11001, Invitrogen, Carlsbad, CA). Nuclei were visualized by Hoechst nuclear stain (Invitrogen, Carlsbad, CA). Sections were mounted onto glass slides and mounted using DABCO mounting media (10 mg of DABCO (D2522; Sigma-Aldrich, St. Louis, MO) in $1 \mathrm{ml}$ of PBS and $9 \mathrm{ml}$ of glycerol). Slides were sealed using nail polish.

\section{Confocal microscopy}

All fluorescence images were captured on Perkin Elmer ERS 6FE spinning disk confocal microscope, and images were processed and analyzed in Volocity version 6.1.1 software (Perkin Elmer, Shelton, CT).

\section{Quantitative real-time PCR analysis}

Quantitative real-time (qRT) PCR analysis of RNA isolated from embryonic day 9.5 embryos was performed 
using iQ SYBR Green Supermix (Bio-Rad, Hercules, CA,) with the CFX96 real-time PCR detection system (Bio-Rad) as previously reported [22]. Primer pairs (from $5^{\prime}$ to $3^{\prime}$ ) used for qRT-PCR analysis were as follows: Patched-1: GCCAAGCCCTAAAAAAAT and ACCACA ATCAATCTCCTG (previously reported by Croyle et al. [23]; Gli1: TCGACCTGCAAACCGTAATCC and TCCT AAAGAAGGGCTCATGGTA. The following primers for peptidylprolyl isomerase A (Ppia) were used as an internal control: CAGACGCCACTGTCGCTTT and TG TCTTTGGAACTTTGTC (both Gli and Ppia primers previously reported by Hellstrom et al. [24]). Samples were run in triplicate using RNA from at least three different embryos per genotype.

\section{Statistical analysis}

The difference in gene expression between Cluap $1^{\text {WT }}$ and Cluap $1^{K O}$ embryos was assessed using Student's $t$ test on log-transformed values of the relative normalized quantity of template. Significance was established at $P<$ 0.01 . All calculations were performed using Microsoft Excel.

\section{Results}

Loss of Cluap1 is embryonically lethal

Analysis of the homolog of Cluap1 in C. elegans and zebrafish suggests that it is a component of the intraflagellar transport (IFT) machinery necessary for cilia assembly [17]. To assess if this role for Cluap1 is evolutionarily conserved in mammals, a mouse embryonic stem cell line harboring a $\beta$-galactosidase cassette in intron 2 of Cluap1 was obtained and used to generate a knockout mouse line (hereinafter referred to as Cluap1 $^{K O}$ ) (Figure 1A,B). We crossed Cluap1 heterozygotes (Cluap1 $^{\text {Het }}$ ) to produce homozygous Cluap1 knockouts $\left(\right.$ Cluap $\left.1^{\text {KO }}\right)$. More than 15 different Cluap $1^{\text {Het }}$ intercrosses producing over 150 offspring failed to yield any $C l u a p 1^{K O}$ pups, indicating that loss of Cluap1 is embryonically lethal. To determine the timing of Cluap1 mutant lethality, we set up timed pregnancies [embryonic day 0.5 (E0.5) was the morning of copulatory plug visualization]. This revealed no surviving Cluap $^{K O}$ embryos between E10.5 and E18.5. However, surviving Cluap1 $1^{K O}$ embryos (determined by the presence of a beating heart) were detected at E9.5. Analysis of Cluap $1^{K O}$ embryos revealed that they were runted and exhibited enlarged pericardial sacs (Figure 1C, arrow). Most striking, however, was the failure of proper embryonic turning marked with kinks in the neural tube (Figure 1C, asterisk) when compared to wild-type siblings $\left(\right.$ Cluap $\left.1^{W T}\right)$. These phenotypes are similar to those of known IFT mutants $[25,26]$. To determine if our Cluap1 ${ }^{K O}$ allele was a null, we looked at both transcript and protein levels in Cluap $1^{K O}$ embryos. Both analyses demonstrated a total loss of Cluap1 transcript and protein in the Cluap $1^{K O}$ embryos (Figure 1D, E, Additional file 1: Figure S1).

\section{Cluap1 is widely expressed in the adult and embryonic mouse}

Previous studies of IFT genes have indicated they are widely expressed [27,28]. Similarly, RT-PCR analysis revealed Cluap1 expression in all tissues tested (Figure 2A). We analyzed spatial expression of Cluap1 using the $\beta$-galactosidase ( $\beta$-gal) reporter present in the Cluap1 ${ }^{K O}$ allele (Figure 1A). Heart, kidney, and lung tissue taken from Cluap $1^{\text {Het }}$ mice showed $\beta$-galactosidase-positive staining (Figure $2 \mathrm{~B}$ ). The expression of Cluap1 is markedly elevated in multiciliated cells such as the bronchioles of the lung (Figure 2B) and ependymal cells of the brain (data not show), but was absent in the alveolar parenchyma (Figure 2B, asterisks). Cluap1 $\beta$-gal expression was also detected in cells with a single primary cilium (Figure 2B, heart and kidney).

We also stained Cluap $1^{W T}$ and Cluap $1^{\text {Het }}$ embryos at embryonic day 9.5, the last time point in which Cluap $1^{\text {KO }}$ embryos are viable. In Cluap $1^{\text {Het }}$ embryos, $\beta$ galactosidase-positive staining was present along the entire anterior-posterior axis (Figure 2B). These results show that Cluap1 is widely expressed in ciliated tissues.

\section{Cluap1 localizes to the primary cilia in vitro}

To assess Cluap1 subcellular localization, we coimmunolabled NIH3T3 cells with our Cluap1 antibody and the cilia marker acetylated $\alpha$-tubulin (Figure 3A-C). Cluap1 localizes to the primary cilia and was visualized throughout the length of axoneme (Figure 3B,C). We confirmed the cilia localization in two additional independent cell lines derived from renal collecting ducts of adult mice (176-6C cells, Figure 3D-F and IMCD3 cells, Figure 3G-I).

\section{Cluap ${ }^{K O}$ embryos lack primary cilia}

The improper embryonic turning and enlarged pericardial sac phenotypes seen in Cluap $1^{K O}$ animals are similar to phenotypes observed in IFT mutants $[25,26]$. This finding combined with the cilia localization of Cluap1 raised the possibility that mammalian Cluap1 is required for ciliogenesis. To test this hypothesis, E9.5 Cluap ${ }^{K O}$ embryos were immunostained for the presence of cilia. Antibodies to acetylated $\alpha$-tubulin showed a complete absence of cilia in sections of the lateral plate mesenchyme of Cluap1 ${ }^{K O}$ embryos (Figure 4B,D,F), while in control Cluap ${ }^{W T}$ embryos, a single primary cilium was detected on nearly every cell (Figures 4A,C,E). Thus, Cluap1 is necessary for cilia formation in mice. Also in Cluap1 mutant cells, the immunofluorescence showed an increase in acetylated $\alpha$-tubulin staining similar to another Ift mutant [26]. 


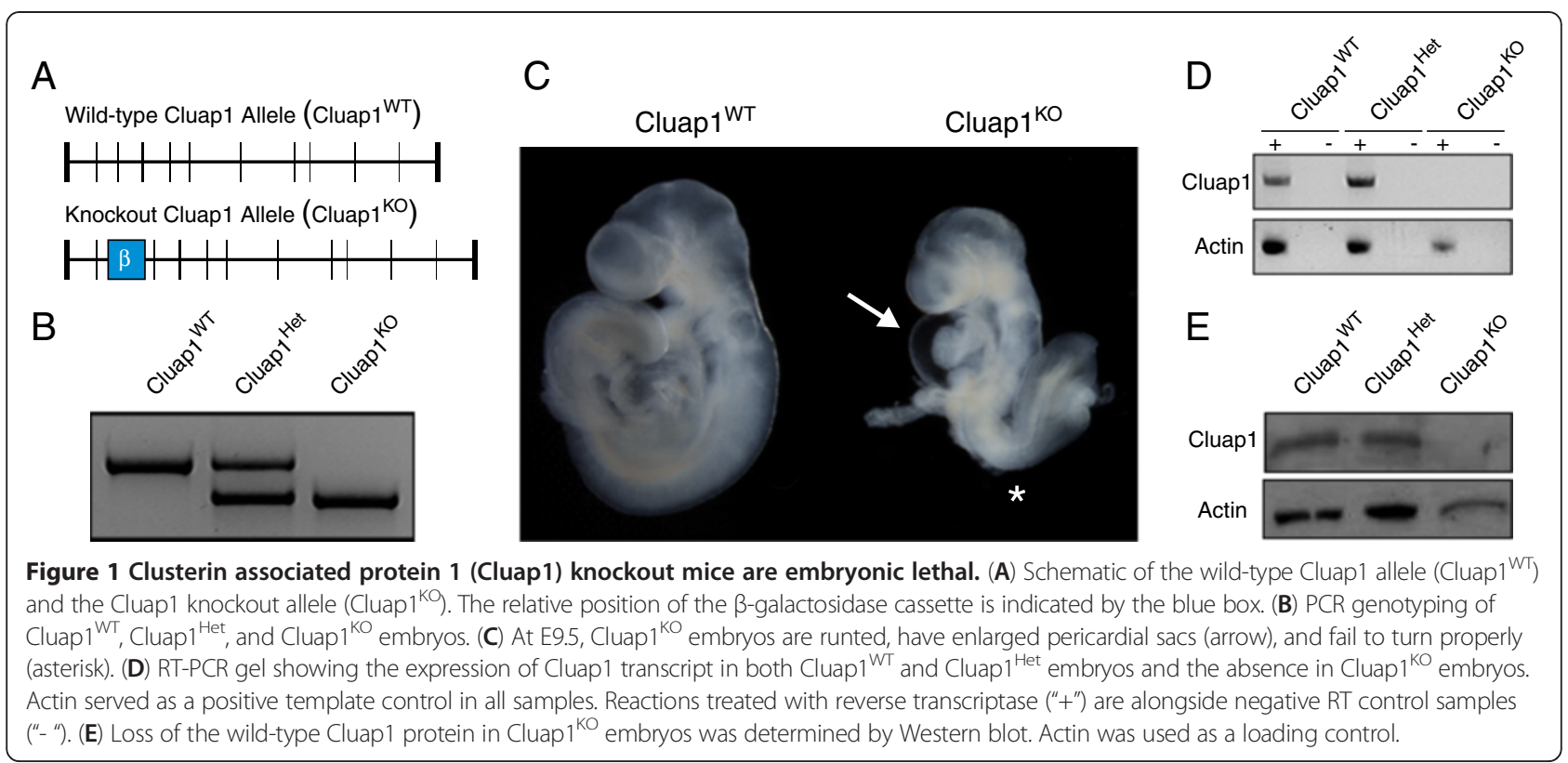

\section{Loss of Cluap1 disrupts Sonic hedgehog signaling}

Cilia are necessary for normal activation as well as repression of the Sonic hedgehog signaling (Shh) pathway, and the phenotypes in Cluap1 mutants are consistent with defects in Hh activity [29]. To evaluate this possibility, we performed immunofluorescence analysis on the neural

A
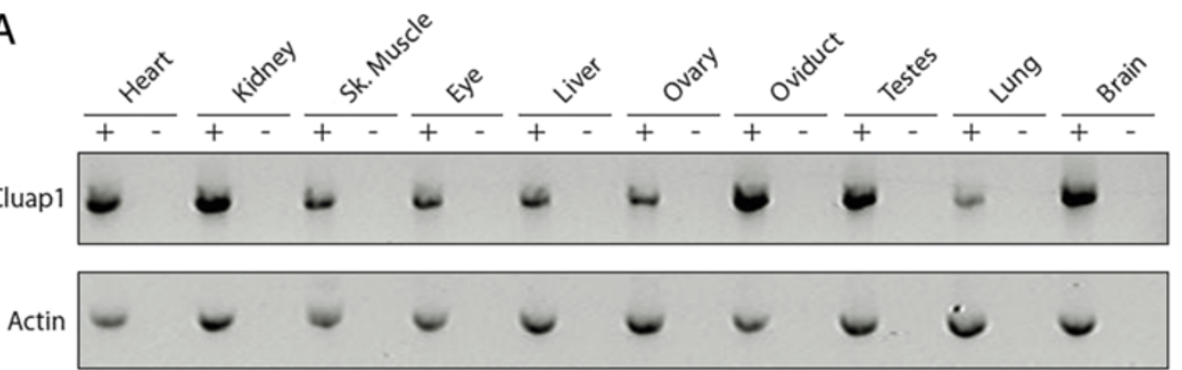

B

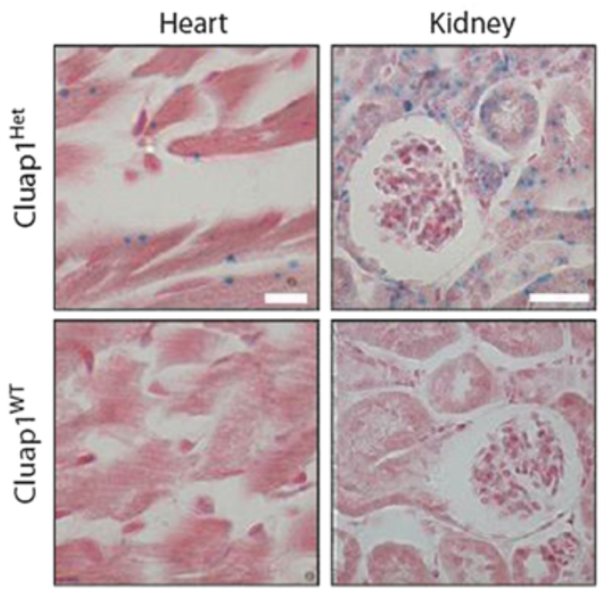

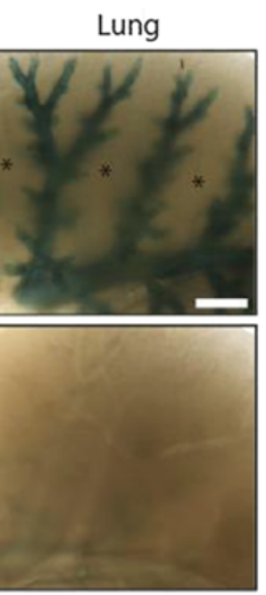

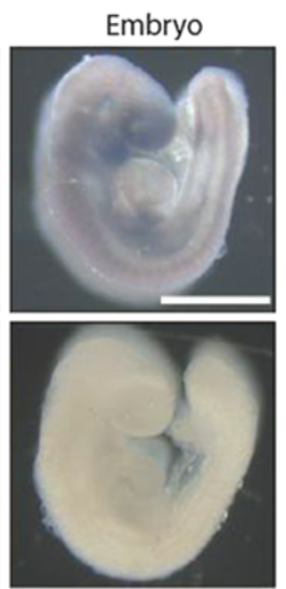

Figure 2 Cluap1 is expressed in ciliated cells with a wide tissue distribution. (A) RT-PCR gel showing expression of Cluap 1 in the indicated tissues; Sk. Muscle, skeletal muscle. Actin is used as a positive control. Reactions treated with reverse transcriptase ("+") are alongside negative RT control samples ("- "). (B) $\beta$-Galactosidase staining assay showing Cluap1 expression in Cluap1 ${ }^{\text {Het }}$ tissue in the ventricles of the heart, cortex of the kidney, lung tissue, and whole E9.5 embryo. Cluap1 ${ }^{\text {WT }}$ control tissue samples. Heart and kidney sections were counterstained in nuclear fast red. Scale bars are $10 \mu \mathrm{m}$ in heart sections, $30 \mu \mathrm{m}$ in kidney sections, and 1,000 $\mu \mathrm{m}$ for whole lung tissues and embryos. 


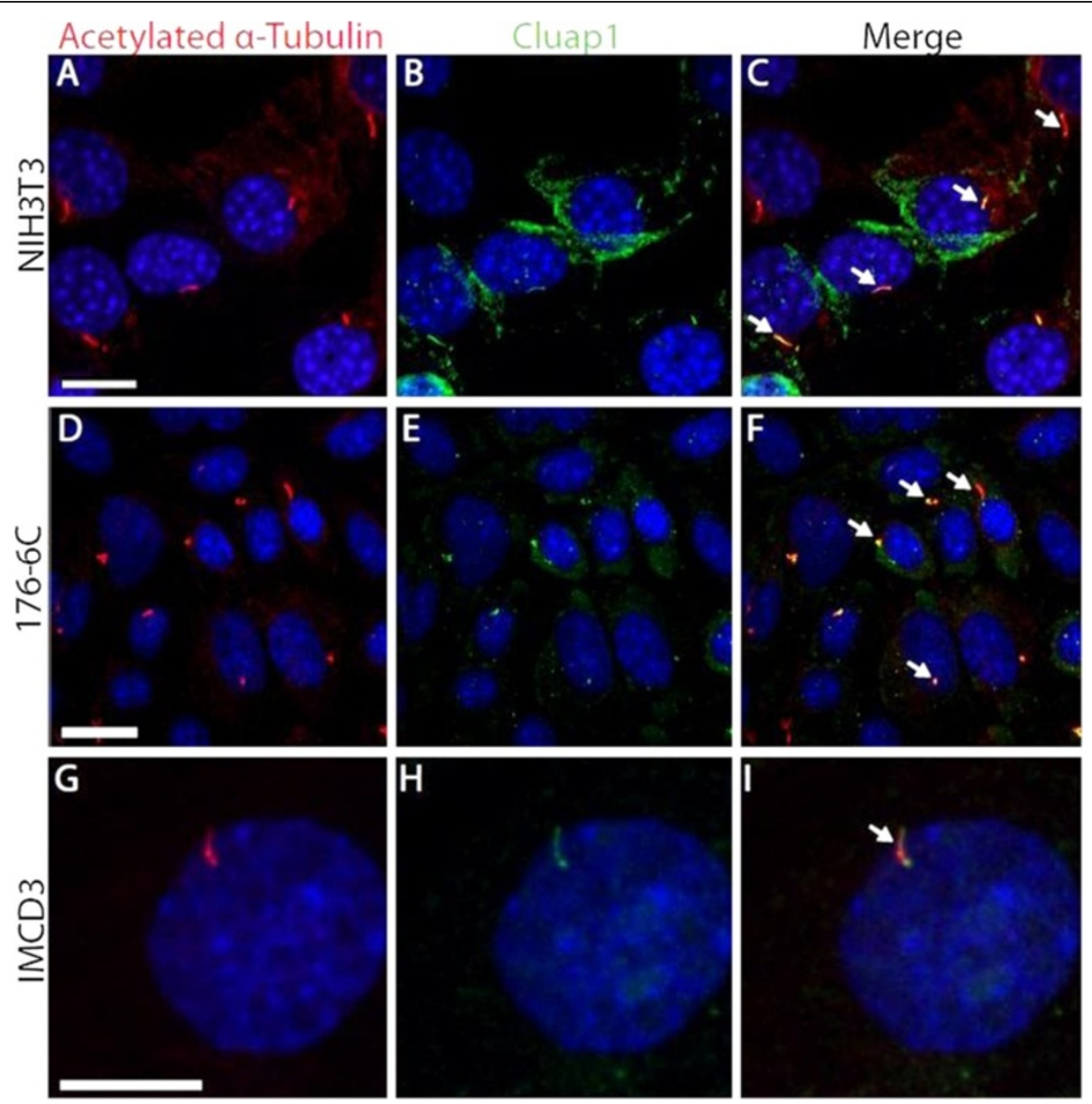

Figure 3 Cluap1 localizes to primary cilia in vitro. Antibody against acetylated a-tubulin (red) and Cluap1 (green) label primary cilia (arrows) in (A-C) NIH3T3 cells (scale bars are $14 \mu \mathrm{m}$ ). (D-F) 176-6C collecting duct epithelium (scale bars are 21 Mm) and (G-I) IMCD3 cells (scale bars are $20 \mu \mathrm{m}$ ). Arrows indicate primary cilium. Nuclei are stained blue with Hoechst.

tubes of E9.5 Cluap1 ${ }^{K O}$ embryos. As expected, Cluap1 ${ }^{\text {WT }}$ embryos possessed a properly defined Shh immunopositive floorplate (Figure 5A,E arrowhead). In contrast, Cluap ${ }^{K O}$ embryos stained positive for Shh ligand, but lacked a defined Shh positive floorplate (Figure 5B,F). Furthermore, staining for Arl13b, a small GTPase that localizes to primary cilia and is necessary for Shh signaling, confirmed an absence of cilia in the neural tubes of Cluap $^{K O}$ embryos (Figure 5D) [30,31]. To further confirm defects in Hh signaling, whole embryos were analyzed for overall Shh pathway activity by qRT-PCR analysis of Patched-1 and Gli1, two downstream target genes induced by Hh. Cluap ${ }^{K O}$ samples showed a significant reduction in both Patched-1 and Gli1 (53.3\% and 20.8\% of wild-type transcript levels, respectively; $p<0.01$, Figure 6). Aside from indicating a defect in the Shh pathway, the downregulation of Patched-1 and Gli1 is also informative about the role of Cluap1 within the cilium itself. As previously reported, loss of function mutations in IFT complex B genes cause a downregulation of Patched-1 and the Gli1 transcription factors. Conversely, mutations in genes encoding IFT A complex proteins cause an increase in the Gli1 and Patched-1 expression [32-34]. Thus, these data indicate that Cluap $1^{K O}$ embryos are defective in Sonic hedgehog signaling most likely because of the loss of IFT $\mathrm{B}$ complex function.

\section{Discussion}

Previous data implicate homologs of Cluap1 in cilia assembly. For example, in C. elegans, the Cluap1 homolog $d y f-3$ is necessary for normal cilia structure, with mutant worms failing to assemble the cilia distal segment [13]. Dyf-3 mutant worms also display defects in ciliaregulated behaviors [12]. Similarly, in zebrafish, qilin/ Cluap1 mutant cilia degenerate in the pronephric duct, leading to subsequent cystogenesis $[14,16]$. Here we provide the first evidence that mammalian Cluap1 is also a cilia protein required for cilia formation and show that mutants have characteristics consistent with Cluap1 being an IFT B complex protein. 

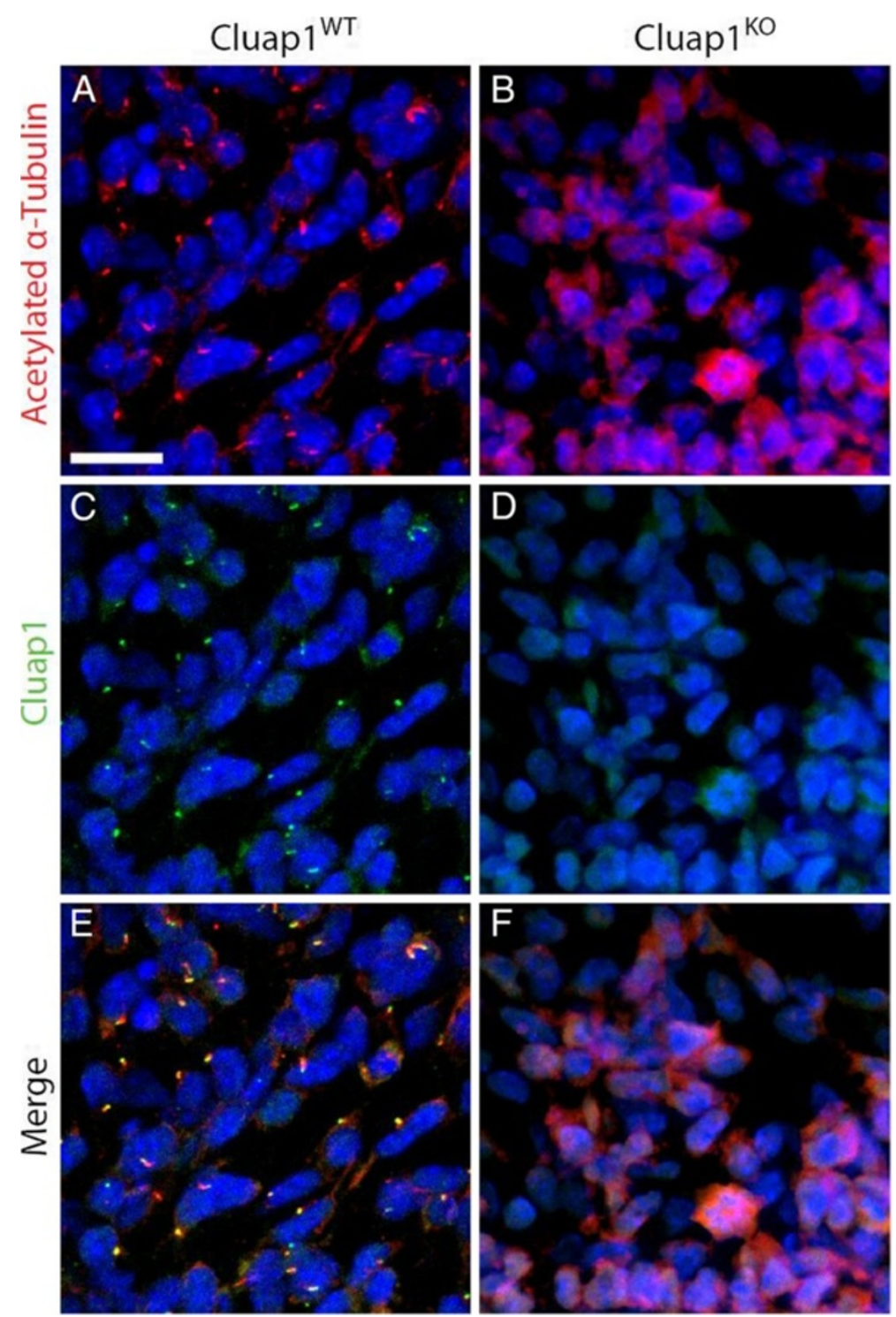

Figure 4 Cluap $^{\mathrm{KO}}$ embryos fail to form primary cilia. (A,C,E) Cluap $1^{\mathrm{WT}}$ E9.5 embryos were immunolabeled for the cilia marker acetylated a-tubulin (red) and Cluap1 (green) in the lateral plate mesenchyme of Cluap1 ${ }^{\mathrm{WT}}$ embryos. (B,D,F) Cluap ${ }^{\mathrm{KO}}$ embryos show a total loss of cilia in the same region. Hoechst nuclear stain in blue. Scale bar is $31.5 \mu \mathrm{m}$.

In addition to being runted, $\mathrm{Cluap}^{K O}$ mutants also failed to be properly turned by E9.5 and have an enlarged pericardial sac, indicating that cardiac insufficiency could be contributing to the midgestational lethality. Defects in embryonic turning with altered leftright axis specification along with an enlarged pericardial sac have been observed in several IFT mutant mouse models [25,26,35]. Aside from having a known role in left-right asymmetry of the heart, cilia have also been implicated in being necessary for early cardiac development through the Sonic hedgehog (Shh) signaling pathway $[36,37]$. Thus, it remains possible that a defect in Shh signaling during heart development could be driving the pericardial defects we observe in Cluap $1^{K O}$ embryos.
In mice, deletion of Cluap1 causes a total loss of cilia within the developing embryo, but this phenotype diverges slightly from studies of Cluap1 homologs in other model organisms. An initial publication in zebrafish stated that mutants of the Cluap1 homolog, qilin, were still capable of cilia assembly, leading to speculation that the protein has an accessory role in cilia maintenance or signaling $[14,19]$. This belief was further supported by the fact that the Chlamydomonas homolog of Cluap1 was not found in biochemical analysis of IFT particles isolated from this organism's flagella $[4,5]$. A follow-up report on the function of qilin in zebrafish did demonstrate that cilia in qilin mutants degenerate over time [16]. However, an independent study utilizing a morpholino approach to knockdown 

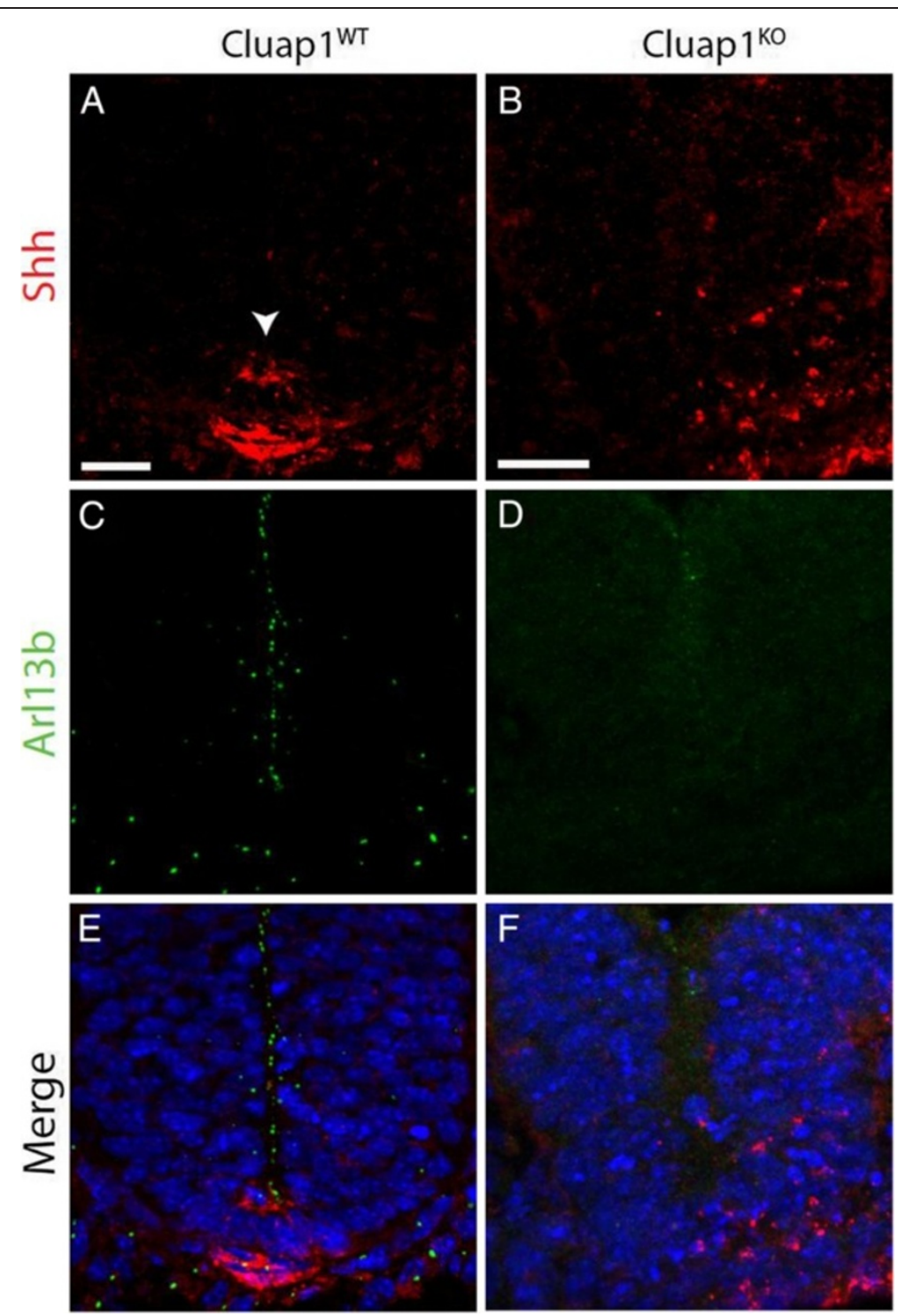

Figure 5 Cluap $^{\mathrm{KO}}$ embryos have defects in floorplate induction. (A,C,E) Cluap $1^{\mathrm{WT}}$ E9.5 embryos stained for Arl13b (green) show cilia in the neural tube and surrounding tissue. Staining for Sonic hedgehog ligand (red) shows a Shh immunopositive floorplate. (B,D,F) Cluap $1^{\mathrm{KO}}$ embryos show an absence of cilia as indicated by the lack of Arl13b staining. Note the lack of a clearly defined Shh immunopositive floorplate. Hoechst nuclear stain in blue. Scale bars are $21 \mu \mathrm{m}$.

qilin revealed a more severe developmental phenotype with pronounced cilia loss [15]. This suggests maternal contribution of qilin mRNA in the genetic mutant is masking a role for qilin in early ciliogenesis. Our Cluap $1^{K O}$ mutant mouse provides further support that this protein has an important role in ciliogenesis conserved across a diverse range of eukaryotic species.

Analysis of the Cluap1 $^{K O}$ mutant mice revealed that the Shh signaling pathway is severely disrupted. Cluap $1^{K O}$ embryos lack a Shh-positive floorplate by E9.5 and have markedly reduced levels of Patched-1 and Gli1 mRNA. Significantly, mutations affecting complex A or complex B IFT proteins have different effects on the activity of the
Shh pathway. IFT B gene mutations show a decrease in Shh signaling activity, while loss of IFT A genes leads to increased levels of Shh signaling [32-34]. Thus, the complete loss of cilia seen in Cluap $1^{K O}$ mutants combined with the reduction in Patched-1 and Gli1 expression implies that Cluap1 is a component to the IFT B complex involved in anterograde cilia transport. However, we cannot unequivocally exclude a role for Cluap1 in ciliogenesis outside of IFT complex B.

\section{Conclusions}

This study demonstrates a highly conserved role for mammalian Cluap1 in cilia biology. Cluap1 is necessary 


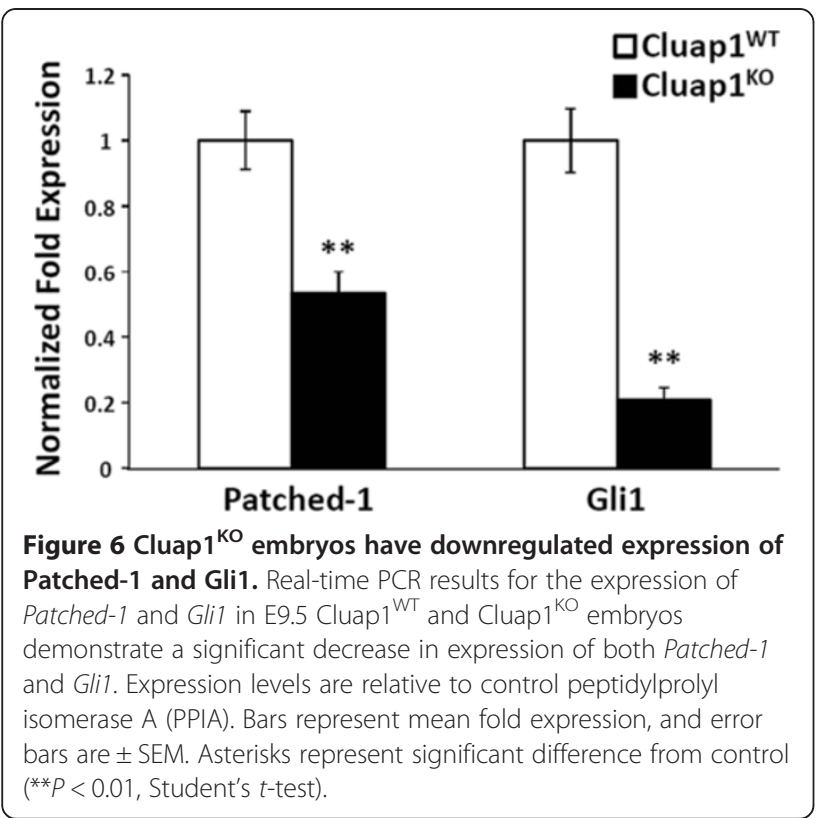

for proper mouse development, is expressed with a wide tissue distribution, and the protein localizes predominantly to the cilium axoneme. Cluap $1^{K O}$ mutant embryos display an enlarged pericardial sac and have defects in neural tube development, possibly related to impaired Shh signaling activity. Importantly, these findings on the role of Cluap1 in ciliogenesis and cilia-mediated signaling support the possibility of Cluap1 being a candidate loci affected in human ciliopathy patients.

\section{Additional file}

Additional file 1: Figure S1. Western blot analysis showing loss of Cluap1 protein expression in Cluap1 null embryos. A higher molecular weight nonspecific band is also detected but is not altered in Cluap1 mutant embryos.

\section{Abbreviations}

IFT: Intraflagellar transport; Cluap1: Clusterin associated protein 1; Shh: Sonic hedgehog; WT: Wild-type; Het: Heterozygous; KO: Knockout.

\section{Competing interests}

The authors have no conflicts or competing interests to disclose.

\section{Authors' contributions}

RCP and NFB designed and performed experiments and wrote the manuscript. WRL performed the experiments. RAK created the mouse model. BKY designed experiments and wrote the manuscript. All authors read and approved the final manuscript.

\section{Acknowledgements}

We thank Dr. Tamara Caspary for the Arl13b antibody gift. This work was supported in part by T32 graduate training award (T32 GM008111, BKY) to RCP and F32 postdoctoral awards (F32 DK088404) to NFB. The UAB Transgenic Mouse Facility and RAK are supported by NIH P30 CA13148, P30 AR048311 and P30 DK074038. We also would like to thank Mandy J. Croyle for technical assistance and Erik Malarkey for assistance with statistical analysis.

\section{Author details}

'Department of Cell, Developmental and Integrative Biology, University of Alabama at Birmingham, 1918 University Blvd., Birmingham, AL 35294, USA. ${ }^{2}$ Department of Genetics, University of Alabama at Birmingham, 720 20th St S., Birmingham, AL 35294, USA

Received: 26 June 2012 Accepted: 7 August 2012

Published: 1 November 2012

\section{References}

1. Rosenbaum JL, Witman GB (2002) Intraflagellar transport. Nat Rev Mol Cell Biol 3:813-825

2. Kozminski KG, Johnson KA, Forscher $P$, Rosenbaum لL (1993) A motility in the eukaryotic flagellum unrelated to flagellar beating. Proc Natl Acad Sci USA 90:5519-5523

3. Pedersen LB, Rosenbaum $\mathrm{L}$ (2008) Intraflagellar transport (IFT) role in ciliary assembly, resorption and signalling. Curr Top Dev Biol 85:23-61

4. Cole DG, Diener DR, Himelblau AL, Beech PL, Fuster JC, Rosenbaum JL (1998) Chlamydomonas kinesin-II-dependent intraflagellar transport (IFT): IFT particles contain proteins required for ciliary assembly in caenorhabditis elegans sensory neurons. J Cell Biol 141:993-1008

5. Piperno G, Mead K (1997) Transport of a novel complex in the cytoplasmic matrix of chlamydomonas flagella. Proc Natl Acad Sci USA 94:4457-4462

6. Pazour GJ, Dickert BL, Vucica Y, Seeley ES, Rosenbaum JL, Witman GB, Cole DG (2000) Chlamydomonas IFT88 and its mouse homologue, polycystic kidney disease gene $\mathrm{tg} 737$, are required for assembly of cilia and flagella. Cell Biol 151:709-718

7. Taulman PD, Haycraft CJ, Balkovetz DF, Yoder BK (2001) Polaris, a protein involved in left-right axis patterning, localizes to basal bodies and cilia. Mol Biol Cell 12:589-599

8. Huangfu D, Liu A, Rakeman AS, Murcia NS, Niswander L, Anderson KV (2003) Hedgehog signalling in the mouse requires intraflagellar transport proteins Nature 426:83-87

9. Haycraft CJ, Banizs B, Aydin-Son Y, Zhang Q, Michaud EJ, Yoder BK (2005) Gli2 and Gli3 localize to cilia and require the intraflagellar transport protein polaris for processing and function. PLoS Genet 1:e53

10. Badano JL, Mitsuma N, Beales PL, Katsanis N (2006) The ciliopathies: an emerging class of human genetic disorders. Annu Rev Genomics Hum Genet 7:125-148

11. Sharma N, Berbari NF, Yoder BK (2008) Ciliary dysfunction in developmental abnormalities and diseases. Curr Top Dev Biol 85:371-427

12. Starich TA, Herman RK, Kari CK, Yeh WH, Schackwitz WS, Schuyler MW, Collet J, Thomas JH, Riddle DL (1995) Mutations affecting the chemosensory neurons of caenorhabditis elegans. Genetics 139:171-188

13. Murayama T, Toh Y, Ohshima Y, Koga M (2005) The dyf-3 gene encodes a novel protein required for sensory cilium formation in caenorhabditis elegans. J Mol Biol 346:677-687

14. Sun Z, Amsterdam A, Pazour GJ, Cole DG, Miller MS, Hopkins N (2004) A genetic screen in zebrafish identifies cilia genes as a principal cause of cystic kidney. Development 131:4085-4093

15. Aanstad P, Santos N, Corbit KC, Scherz PJ, Trinh LA, Salvenmoser W, Huisken J, Reiter JF, Stainier DYR (2009) The extracellular domain of smoothened regulates ciliary localization and is required for high-level Hh signaling. Curr Biol 19:1034-1039

16. Li J, Sun Z (2011) Qilin is essential for cilia assembly and normal kidney development in zebrafish. PLoS One 6:e27365

17. Ou G, Qin H, Rosenbaum JL, Scholey JM (2005) The PKD protein qilin undergoes intraflagellar transport. Curr Biol 15:R410-R411

18. Takahashi M, Lin YM, Nakamura Y, Furukawa Y (2004) Isolation and characterization of a novel gene CLUAP1 whose expression is frequently upregulated in colon cancer. Oncogene 23:9289-9294

19. Marshall WF (2004) Human cilia proteome contains homolog of zebrafish polycystic kidney disease gene gilin. Curr Biol 14:R913-R914

20. Ishikura H, Ikeda H, Abe H, Ohkuri T, Hiraga H, Isu K, Tsukahara T, Sato N, Kitamura H, Iwasaki N et al (2007) Identification of CLUAP1 as a human osteosarcoma tumor-associated antigen recognized by the humoral immune system. Int J Oncol 30:461-467

21. Sharma N, Kosan ZA, Stallworth JE, Berbari NF, Yoder BK (2011) Soluble levels of cytosolic tubulin regulate ciliary length control. Mol Biol Cell 22:806-816 
22. Croyle MJ, Lehman JM, O'Connor AK, Wong SY, Malarkey EB, Iribarne D, Dowdle WE, Schoeb TR, Verney ZM, Athar M et al (2011) Role of epidermal primary cilia in the homeostasis of skin and hair follicles. Development 138:1675-1685

23. Levi B, James AW, Nelson ER, Brugmann SA, Sorkin M, Manu A, Longaker MT (2011) Role of Indian hedgehog signaling in palatal osteogenesis. Plast Reconstr Surg 127:1182-1190

24. Hellstrom A, Perruzzi C, Ju M, Engstrom E, Hard AL, Liu JL, AlbertssonWikland K, Carlsson B, Niklasson A, Sjodell L et al (2001) Low IGF-I suppresses VEGF-survival signaling in retinal endothelial cells: direct correlation with clinical retinopathy of prematurity. Proc Natl Acad Sci USA 98:5804-5808

25. Murcia NS, Richards WG, Yoder BK, Mucenski ML, Dunlap JR, Woychik RP (2000) The oak ridge polycystic kidney (orpk) disease gene is required for left-right axis determination. Development 127:2347-2355

26. Berbari NF, Kin NW, Sharma N, Michaud EJ, Kesterson RA, Yoder BK (2011) Mutations in Traf3ip1 reveal defects in ciliogenesis, embryonic development, and altered cell size regulation. Dev Biol 360:66-76

27. Baker SA, Freeman K, Luby-Phelps K, Pazour GJ, Besharse JC (2003) IFT20 links kinesin II with a mammalian intraflagellar transport complex that is conserved in motile flagella and sensory cilia. J Biol Chem 278:34211-34218

28. Rix S, Calmont A, Scambler PJ, Beales PL (2011) An Ift80 mouse model of short rib polydactyly syndromes shows defects in hedgehog signalling without loss or malformation of cilia. Hum Mol Genet 20:1306-1314

29. Goetz SC, Anderson KV (2010) The primary cilium: a signalling centre during vertebrate development. Nat Rev Genet 11:331-344

30. Caspary T, Larkins CE, Anderson KV (2007) The graded response to sonic hedgehog depends on cilia architecture. Dev Cell 12:767-778

31. Larkins CE, Aviles GD, East MP, Kahn RA, Caspary T (2011) Arl13b regulates ciliogenesis and the dynamic localization of Shh signaling proteins. Mol Biol Cell 22:4694-4703

32. Qin JA, Lin $Y L$, Norman $R X$, Ko HW, Eggenschwiler JT (2011) Intraflagellar transport protein 122 antagonizes sonic hedgehog signaling and controls ciliary localization of pathway components. Proc Natl Acad Sci USA 108:1456-1461

33. Tran PV, Haycraft CJ, Besschetnova TY, Turbe-Doan A, Stottmann RW, Herron BJ, Chesebro AL, Qiu H, Scherz PJ, Shah JV et al (2008) THM1 negatively modulates mouse sonic hedgehog signal transduction and affects retrograde intraflagellar transport in cilia. Nat Genet 40:403-410

34. Huangfu D, Anderson KV (2005) Cilia and hedgehog responsiveness in the mouse. Proc Natl Acad Sci USA 102:11325-11330

35. Cui C, Chatterjee B, Francis D, Yu Q, SanAgustin JT, Francis R, Tansey T, Henry C, Wang B, Lemley B et al (2011) Disruption of Mks1 localization to the mother centriole causes cilia defects and developmental malformations in Meckel-Gruber syndrome. Dis Model Mech 4:43-56

36. Clement CA, Kristensen SG, Mollgard K, Pazour GJ, Yoder BK, Larsen LA, Christensen ST (2009) The primary cilium coordinates early cardiogenesis and hedgehog signaling in cardiomyocyte differentiation. J Cell Sci 122:3070-3082

37. Nonaka S, Tanaka Y, Okada Y, Takeda S, Harada A, Kanai Y, Kido M, Hirokawa N (1998) Randomization of left-right asymmetry due to loss of nodal cilia generating leftward flow of extraembryonic fluid in mice lacking KIF3B motor protein. Cell 95:829-837

doi:10.1186/2046-2530-1-20

Cite this article as: Pasek et al: Mammalian Clusterin associated protein

1 is an evolutionarily conserved protein required for ciliogenesis. Cilia 2012 1:20.

\section{Submit your next manuscript to BioMed Central and take full advantage of:}

- Convenient online submission

- Thorough peer review

- No space constraints or color figure charges

- Immediate publication on acceptance

- Inclusion in PubMed, CAS, Scopus and Google Scholar

- Research which is freely available for redistribution 